\title{
Chapter 8 \\ Predicting Model of Rockburst Based on Nondeterministic Theory
}

\subsection{Introduction}

Predicting is the basis of prevention and controlling of rockburst hazards. According to the predicting results, the feedback design of rock engineering and controlling measures are taken in time. It is of great theoretical and practical value for the safety and efficiency of deep mine. So far, there are many methods to judge rockburst tendency, such as rock integrity coefficient method, strength criterion discrimination method, rock brittleness index method, elastic energy index method, dynamic failure time method, rockburst energy ratio method, impact energy index method, impact tendency criterion method, and resistivity method. Most of these methods and judging indexes, which is only considered the individual factors, were one-sidedness, limitations and complications. Therefore, the influencing factors of rockburst are comprehensively based on the non-deterministic theory for established a more accurate rockburst predicting model. Rockburst is a complex dynamic instability phenomenon (Hedley 1992), which can occur during underground excavation in areas with large in situ stress. As a result of the sudden release of accumulated strain energy, rocks can be come loose, crack, and even eject violently (Canadian Rockburst Research Program 1996). As a result, rockbursts were considered a major technical challenge in deep mining. Duo to the characteristic of sudden, disruptive, and complex, the accurate prediction of rockbursts was difficult and an urgent problem need to be solved (Blake et al. 2003).

The phenomenon was discussed extensively by many scholars. Rockburst tendency is an important metric to quantify the risk and potential intensity of occurrences and grade the hazard of an affected mine. However, there are still no accurate prediction methods or effective control measures. In recent decades, many meaningful advances have been made by many scholars (Singh 1989; Dou et al. 2009; Marek 2009; Patynska et al. 2009; Marian 2011). Rockburst mechanism was better understand using some proposed some criteria, such as strength theory, stiffness theory and energy theory. These models could be explained the origin and mechanism of 
rockbursts, but were hard to apply in practice. In addition, several indexes were proposed to measure rockburst tendency, such as strength and brittleness, burst energy release, impact energy and rock integrity (Hoek et al. 1980; Cook 1965; Wiebols et al. 1968; Tan et al. 1991; Kidybiński 1981; Singh 1988; Hou et al. 1989). These criteria derived from the mechanical parameters obtained by testing rock samples. Some important values were compressive strength, tensile strength, capacity to store and release elastic strain energy, and surrounding rockmass stress and integrity.

In light of rockburst phenomenon complexity, the use of a single parameter was insufficient for predicting rockburst. Though AE, chip drilling, removal, vibration, and resistance methods were proposed and applied, each parameter was lacking in predictive power under isolation. As a multifactor, coupling induced dynamic hazard, it was essential to establish a calculation method to evaluate rockburst tendency involving the proper parameters. However, few studies were tried to combine the various factors relating to rockburst hazard. Recently, some interesting models were derived using artificial intelligence, such as a neural network (Chen et al. 2002), fuzzy theory (Adoko et al. 2013; Wang et al. 2015), and distance discriminant analysis method (Gong et al. 2007), along with other integrated analysis methods. These research results indicated that the occurrence of rockbursts was closely related to the mechanical properties of rockmass, the geological structure, and the surrounding stress. However, these attempts had not yet formed a complete theoretical system. Based on the Bayesian theory and Fuzzy element-matter theory, several critical factors were integrated into a single model for predicting rockburst tendency in this chapter.

Bayesian theory, which is successfully applied in many fields, provides a clear and a flexible method for making predictions using incomplete knowledge. Heckerman (Heckerman 1990) used a Bayesian framework to improve the process of medical diagnosis. Making full use of its strong information processing ability (Weidl et al. 2003), a Bayesian network was applied to the monitoring and management of industrial production processes. A Bayesian model was utilized for choosing investment ventures, and displayed a good ability to cope with future uncertainty (Kemmerer et al. 2002). In addition, Bayesian theory was used to identify faults in a computer system (Jensen et al. 2001). It was attempt that the tendency was predicted more precisely using these incomplete indexes of rockburst occurrence.

Professor Cai (1994) analyzed a large number of examples found that people in dealing with incompatibility issues must take things, features and the corresponding value to consider together. The main idea of this method was to make things to 'things, features, values' to describe and analyze. Matter-element analysis is an effective way to study matter-element and to solve incompatible problems in the real world. If the magnitude of matter is ambiguous, it constitutes a fuzzy incompatibility problem. Fuzzy matter-element analysis is the combination of fuzzy mathematics, and matter-element analysis can solve this kind of fuzzy things. In recent years, this highly practical theory and method were achieved many gratifying results in the field of engineering technology. In addition, artificial intelligence methods were used, 
such as fuzzy inference system (FIS) and adaptive neuro-fuzzy inference systems (Adoko 2013) and Rough set theory and genetic algorithms (Yu 2009). These were seismological theory and methods were used to predict the rockburst such as the peak velocity and dynamic energy, the seismic risk assessment method and mining and seismological parameters (Srinivasan et al. 1997; Li et al. 2011; Stewart 1995). The above research works indicated that the occurrence of rockburst was closely related to the strength of surrounding rockmass, geomechanics, geological structure, hydrogeology, and the construction sequence. Matter-element analysis theory was primarily used to study the problem of in compatibility (Wang et al. 2015). It could be also used for solving multiple-parameter evaluation problems by formalizing the problem and establishing the corresponding matter-element (Cai 1994; David et al. 1997; Chen et al. 2007; Liu et al. 2007). The improved fuzzy matter-element evaluation method was used to assess water quality, which achieved more reliable results than that using the traditional method (Liu et al. 2012). Based on the matter-element method (He et al. 2011) designed a model to evaluate the urban power net work planning, and Zhu (2010) analyzed coefficients of evaluation in rockburst. The empirical analysis showed that this model was reliable and feasible.

Therefore, in this chapter, Bayesian theory was demonstrated to be a reliable approach to address complex problems involving many variables with large uncertainties, and models that considered a multi-parameter space were better suited to predicting rockburst tendency than single-variable models. The main factors affecting of risk and intensity of rockbursts were used to make a Bayesian model. On the other hand, the main influencing factors of rockburst were considered based on the concept of matter-element analysis in combination with the fuzzy set and closeness degree rules. The entropy method was also integrated in the weight calculation in this model. An integrated rockburst multi-index evaluation model was established and used to predict the rockburst tendency in a case study.

\subsection{Predicting Model of Rockburst Based on Bayesian Theory}

\subsubsection{An Overview of Bayesian Theory}

A Bayesian model is a statistical analysis method commonly used to distinguish between types of samples. The primary procedure is based on an artificial familiarity with known samples and possible attendant consequences. Firstly, the empirical probability and covariance of each classification was analysed and calculated. Then, a discriminant function was formulated to grade samples. Finally, a posterior probability was calculated to verify the original evaluation. New samples could be easily classified after being input into model (Ren and Yu 1999; Gao 1999). 


\subsubsection{Empirical Probability}

A sample set can be divided into $k$ categories $\mathrm{G}_{1}, \mathrm{G}_{2}, \ldots \mathrm{G}_{k}$ according to a certain criterion. Assuming each sample has $m$ factors, $\mathrm{x}_{1}, \mathrm{x}_{2}, \ldots \mathrm{x}_{m}$, that are normally distributed, a given sample can be expressed as a $m$-dimensional array $X_{\mathrm{j}}^{(\mathrm{i})}=\left[\left(\mathrm{x}_{1}, \mathrm{x}_{2}, \ldots \mathrm{x}_{m}\right)_{j}^{(i)}\right]^{T}$, where $\mathrm{i}=1,2,3, \ldots k, \mathrm{j}=1,2,3, \ldots \mathrm{n}_{i}$, and $X_{\mathrm{j}}^{(\mathrm{i})} \in G_{i}$.

If there are a sufficient number of samples, the "empirical probability", which is the probability that a single sample will be classified into $G_{i}$, it can be expressed as

$$
p_{i}=\frac{n_{i}}{n_{1}+n_{2}+, \ldots, n_{k}}=\frac{n_{i}}{\sum_{i=1}^{k} n_{i}}
$$

\subsubsection{Mean Values and Covariance}

Moment estimation of mean values and variances can be introduced to generalize the distribution characteristics of $i$-th category:

$$
\begin{gathered}
\mu X^{(\mathrm{i})}=\bar{X}^{(\mathrm{i})}=\frac{1}{n_{i}} \sum_{j=1}^{n_{i}} X_{j}^{(i)} \\
S_{\mathrm{i}}^{2}=\frac{1}{n_{i}-1} \sum_{j=1}^{n_{i}}\left(X_{j}^{(i)}-\bar{X}^{(i)}\right)\left(X_{j}^{(i)}-\bar{X}^{(i)}\right)^{T} \\
\sum=\frac{1}{\sum_{i=1}^{\mathrm{k}}\left(n_{i}-1\right)} \sum_{i=1}^{k}\left(n_{i}-1\right) S_{i}^{2}
\end{gathered}
$$

where $\bar{X}^{(\mathrm{i})}, \mu X^{(\mathrm{i})}, S_{\mathrm{i}}^{2}$ refer to the mean values, expectation of mean values, and covariance of $i$ th category, respectively. Additionally, $\Sigma$ stands for the covariance matrix of overall sample population.

\subsubsection{Empirical Discriminant}

In this Bayesian model, the empirical discriminant of sample classification can be expressed as:

$$
\omega_{\mathrm{i}}(\mathrm{X})=\mu_{\mathrm{i}}^{T} \Sigma^{-1} X-\frac{1}{2} \mu_{\mathrm{i}}^{T} \Sigma^{-1} \mu_{\mathrm{i}}+\ln p_{i}
$$

The discriminating rule can be simplified to be:

If $\omega_{\mathrm{i}}(\mathrm{X})=\max _{1 \leq j \leq k} \omega_{\mathrm{j}}(\mathrm{X})$, then $X \in G_{i}$. 


\subsubsection{Posterior Probability and Verification}

A Bayesian distance discriminant method was used to separate the samples. The distance of a given sample $X=\left(\mathrm{x}_{1}, \mathrm{x}_{2}, \ldots \mathrm{x}_{m}\right)^{T}$ to the $i$-th category's centroid can be calculated as:

$$
d_{j}^{2}(X)=\left(X-\mu_{j}\right)^{T} \Sigma^{-1}\left(X-\mu_{j}\right)-2 \ln p_{j}
$$

so the posterior probability that $X$ belongs to the $i$-th category can be calculated as follow:

$$
P\left(G_{\mathrm{j}} \mid X\right)=\frac{\exp \left[-\frac{1}{2} d_{j}^{2}(X)\right]}{\sum_{i=1}^{k} \exp \left[-\frac{1}{2} d_{i}^{2}(X)\right]}
$$

If $P\left(G_{\mathrm{j}} \mid X\right)>50 \%$, then $X \in G_{i}$.

This confirms the previous result.

\subsubsection{Key Factors of Rockburst Tendency}

\subsubsection{Induced Factors of Rockburst}

Numerous engineering datasets showed that rockbursts were usually occurred in hard-rock zones that were mostly intact and exhibited high strength, while there were few rockbursts in soft-rock areas. Thus, the occurrence of rockbursts was strongly related to the mechanical properties of surrounding rockmass. The development and triggering of rockburst was a physical process of gradual energy storage and sudden instability, which showed as a large energy release. Laboratory tests showed that these rocks were brittle but high-strength with linear elastic characteristics. The tests also showed that these rocks had the characteristics of elastic-brittle failure and that the elastic modulus was relative high. As a result, they were prone to brittle failure in the high-stress regime. Excavation could result in stress redistribution and concentration of surrounding rockmass. Once local brittle failure occurs, the accumulated energy was quickly released, caused easily a rockburst.

There was a close relationship between the occurrence of a rockburst and the characteristics of in situ stress concentration. Under the same geological conditions, high stress was concentrated in the local rock. Some rock zones had instead low crustal stress levels. An intact rock with high crustal stress usually had a high elastic modulus, which meaned a large capacity to store strain energy. High stress locations were especially prone to occur rockbursts, especially zones not in a hydrostatic status. In the stress concentration zones, most rockbursts were attributable to the discordance of three dimensional stresses, which leaded to the shear failure of rock, rapid energy release and rockburst. 
Table 8.1 Impact factors of rockburst tendency

\begin{tabular}{l|l|l|l|l|l|l}
\hline Scholars & \multicolumn{7}{|l}{ Impact factors } \\
\hline & $\sigma_{1}$ & $\sigma_{\theta}$ & $\sigma_{1}$ & $\sigma_{\mathrm{c}}$ & $\sigma_{\mathrm{t}}$ & $W_{\text {et }}$ \\
\hline Russenes (1974) & & $\sqrt{ }$ & & $\sqrt{ }$ & & \\
\hline Turchaninov (1981) & & $\sqrt{ }$ & $\sqrt{ }$ & $\sqrt{ }$ & & \\
\hline $\begin{array}{l}\text { Hoek and Brown } \\
(1980)\end{array}$ & & $\sqrt{ }$ & & $\sqrt{ }$ & & \\
\hline Barton (1974) & $\sqrt{ }$ & & & $\sqrt{ }$ & $\sqrt{ }$ & \\
\hline Kidybinski (1981) & & & & & & $\sqrt{ }$ \\
\hline Tao (1987) & $\sqrt{ }$ & & & $\sqrt{ }$ & & \\
\hline Xu (2002) & & $\sqrt{ }$ & & $\sqrt{ }$ & & \\
\hline Wang (1998) & & $\sqrt{ }$ & & $\sqrt{ }$ & & \\
\hline Zhang (1991) & & $\sqrt{ }$ & & $\sqrt{ }$ & & $\sqrt{ }$ \\
\hline
\end{tabular}

Deformations within rockmass were dominated by elastic strain, and most of brittle rock with high strength belonged to this category. Conversely, rockmass dominated by plastic deformation could store less energy. In general, high-strength, brittle rock at underground engineering sites was most likely to induce rockburst.

With respect to energy, rock deformation and failure was the result of energy dissipation and release. The relationship between the dissipated energy and released energy was analysed along the uniaxial loading path; therefore, it might be an effective method that rockburst tendency characterized using the energy index. The deformation characteristics prior to rock failure could be approximately captured by the stress-strain behaviour (Müller 2007).

Rockburst tendency was used to characterize the risk and intensity of these events. The severity could be estimated using different quantitative or qualitative methods. Generally, rockburst intensity was divided into four levels, namely, strong rockburst, moderate rockburst, weak rockburst, and none.

Most scholars studied rockburst tendency using the mechanical properties of field rocks, while some others believed that the stress status of surrounding rockmass was more critical. In the previous literature, one or more factors were used to formulate variables to evaluate rockburst tendency (Wang et al. 2015). Some factors adopted here were listed in Table 8.1. Rockburst tendency was associated most often with $\sigma_{c}$ and $\sigma_{\theta}$, and followed by $\sigma_{1}$ and $W_{\text {et }}$.

There was an extremely complex nonlinear relationship between rockburst and its influencing factors. The selection of rockburst tendency evaluation factor should reflect the basic characteristics of rock and combine the various indexes.

\subsubsection{Critical Factors}

There was a complicated, nonlinear relationship between rockburst and its induced factors. In order to make effective prediction of rockburst, multiple variables were considerated by the integrated indexes. The uniaxial compression strength $\sigma_{\mathrm{c}}$ and 


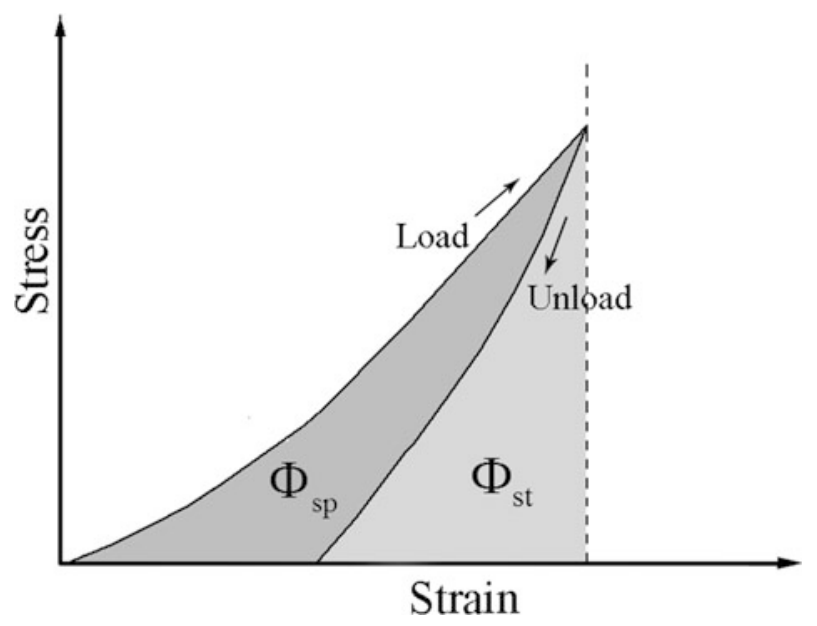

Fig. 8.1 Energy index of rockburst testing. From Kidybiński (1981)

uniaxial tensional strength $\sigma_{\mathrm{t}}$ were the main factors influencing the mechanical properties of rocks. The rock strength-stress ratio $R_{b}$, that is, the brittleness coefficient, could be applied to predict rockburst tendency. Generally, larger $R_{b}$ values were associated with greater rockburst risks. Where $W_{\text {et }}$ was determined by the uniaxial load/unload curve. Obtaining the load/unload path, rock was usually loaded to $70-80 \%$ peak stress, and then unloaded to zero. $W_{\text {et }}$ equaled to the ratio of released energy to the dissipated energy along the load/unload path. As shown in Fig. 8.1, $\Phi_{\mathrm{sp}}$ was the area between the loading path, and $\Phi_{\mathrm{st}}$ was the area under unloading path, and the energy index $W_{\text {et }}$ was calculated as the area ratio $\Phi_{\mathrm{sp}} / \Phi_{\text {st }}$, as shown in Fig. 8.1.

This elastic energy release index of rocks was used to evaluate rockburst tendency. Moreover, the axial stress status of surrounding rockmass was taken into account using Russense's criterion $R_{t}$, which also greatly influenced the risk of rockburst. Multi-paramters, such as physical and mechanical properties, the elastic energy release index, and the stress in the initial rockmass, were considered from different perspectives in these methods. A number of single-variable methods were widely recognized and applied, and three of them are listed in Table 8.2.

Table 8.2 Three classic discriminants for rockburst tendency

\begin{tabular}{l|l|l|l|l|l}
\hline \multirow{2}{*}{ Methods } & Formulas & \multicolumn{4}{l}{ Rockurst grades criterion } \\
\cline { 3 - 6 } & & No & Weak & Medium & Strong \\
\hline $\begin{array}{l}\text { Rock brittleness } \\
\text { index }\end{array}$ & $R_{b}=\frac{\sigma_{c}}{\sigma_{t}}$ & $>40.0$ & $\begin{array}{l}26.7- \\
40.0\end{array}$ & $\begin{array}{l}14.5- \\
26.7\end{array}$ & $<14.5$ \\
\hline Russenses's method & $R_{\theta}=\frac{\sigma_{\theta}}{\sigma_{c}} \sigma_{\theta}=\sigma_{1}-\sigma_{3}$ & $<0.2$ & $0.2-0.3$ & $0.3-0.55$ & $>0.55$ \\
\hline Kidybinski's method & $W_{\mathrm{et}}=\frac{\Phi_{\mathrm{sp}}}{\Phi_{\mathrm{st}}}$ & $<2.0$ & $2.0-3.5$ & $3.5-5.0$ & $>5.0$ \\
\hline
\end{tabular}


The grading criteria for the different methods were presented on Table 8.2. Each row represented a different method, and the columns gave the criteria within each for grading rockbusts into the four intensity levels. Three indexes $R_{b}, R_{\theta}$ and $W_{\text {et }}$ were used as the critical factors in this book.

\subsection{Predicting Model of Rockburst Based on Fuzzy Matter-Element Theory}

\subsubsection{Fuzzy Matter-Element and Composite Fuzzy Matter-Element}

For a given object with $M$ items to be evaluated and the characteristic $C$ is $x$, the sequential matter-element $\mathrm{R}=(M, C, x)$ can be constituted. Assumed that $x$ is fuzzy, $M$ has $n$ characteristics $C_{1}, C_{2}, \ldots, C_{n}$ and the corresponding $n$ values are $x_{1}, x_{2}, \ldots, x_{n}, R$ is called $n$-dimensional fuzzy matter-elements. If $n$ dimensional matter elements are combined with $m$ items together, it is a $n$-dimensional composite fuzzy matter element $R_{n m}$, which can be expressed as:

$$
R_{n m}=\left[\begin{array}{lllll} 
& M_{1} & M_{2} & \cdots & M_{m} \\
C_{1} & \mu\left(x_{11}\right) & \mu\left(x_{12}\right) & \cdots & \mu\left(x_{1 m}\right) \\
C_{2} & \mu\left(x_{21}\right) & \mu\left(x_{22}\right) & \cdots & \mu\left(x_{2 m}\right) \\
\vdots & \vdots & \vdots & \ldots & \vdots \\
C_{n} & \mu\left(x_{n 1}\right) & \mu\left(x_{n 1}\right) & \cdots & \mu\left(x_{n m}\right)
\end{array}\right]
$$

where $\mathrm{R}_{n m}$ is $n$-dimensional matter element for $m$ items, $M_{i}$ is the $i$ th item $(i=1,2$, $\ldots, \mathrm{m}), \mathrm{C}_{j}$ is the $j$ th characteristic $(j=1,2, \ldots, \mathrm{n}), \mu\left(x_{i j}\right)$ is the fuzzy value of $\mathrm{x}_{i j}$, which is the corresponding value for $\mathrm{M}_{i}^{\prime} \mathrm{s} j$-th characteristic $\mathrm{C}_{j}$. In this study, is $\mu\left(x_{i j}\right)$ is standardized using the principle of preferable fuzzy membership grade, which refers to the following methods:

The larger the more optimal model: $\mu_{i j}=X_{i j} / \max X_{i j}$

The smaller the more optimal model:

$$
\mu_{i j}=\frac{\min X_{i j}}{X_{i j}}
$$

where $X_{i j}$ the value of corresponding characteristics $j$ of $i$-th item; $\max X_{i j}, \min X_{i j}$ refer to the maximum and minimum value of all $X_{i j}$, respectively. 


\subsubsection{Standard Fuzzy Matter-Element and Difference Square Composite Fuzzy Matter-Element}

Standard fuzzy matter-element $\mathrm{R}_{0 n}$ is the maximum or minimum value of preferable membership grade for each evaluation method. In this chapter, the maximum value is the optimal value, which also means the preferable membership grade for each index is $1 . \Delta_{i j}(\mathrm{i}=1,2, \ldots, \mathrm{n}, \mathrm{j}=1,2, \ldots, \mathrm{m})$ is the square sum of element difference between standard fuzzy matter-element $R_{0 n}$ and composite fuzzy matter-element $R_{n m}$. The difference square composite fuzzy matter-element is $\Delta_{i j}$, namely $\Delta_{i j}=\left(\mu_{0 j}-\mu_{i j}\right)^{2}$, which can be expressed as:

$$
\Delta_{i j}=\left[\begin{array}{lllll} 
& M_{1} & M_{2} & \cdots & M_{m} \\
C_{1} & \Delta_{11} & \Delta_{12} & \cdots & \Delta_{1 m} \\
C_{2} & \Delta_{21} & \Delta_{22} & \cdots & \Delta_{2 m} \\
\vdots & \vdots & \vdots & \cdots & \vdots \\
C_{n} & \Delta_{n 1} & \Delta_{n 2} & \cdots & \Delta_{n m}
\end{array}\right]
$$

\subsubsection{Weight Coefficients Determined by Entropy Method}

Entropy theory is an objective weighting method that entropy value reflects the chaos level of data. The smaller the entropy value, the smaller the chaos level of data. Therefore, information entropy can be used to evaluate the order degree and utility of obtained information, namely it is to determine the index weight by a judgment matrix constituted by an array of evaluation indexes. It makes the assessment more realistic because it can eliminate human disturbance in the calculation of each index weight. The calculation steps are described as follows (Cai 1994):

(1) Constructing a judgment matrix with $n$ evaluation indexes for $m$ matters

$$
\mathrm{R}=\left(x_{i j}\right)_{n m} \quad(i=1,2, \ldots, n ; j=1,2, \ldots, m)
$$

(2) Normalizing judgment matrix to get the normalized judgment matrix B

$$
b_{i j}=\frac{x_{i j}-x_{\min }}{x_{\max }-x_{\min }}
$$


where $x_{\max }$ and $x_{\min }$ are the most satisfied and the most unsatisfied value for different matters under same method, respectively. For example, the smaller the value the more satisfied or the larger the value the more unsatisfied.

(3) According to the definition of entropy for $n$ evaluation indexes of matters, the entropy of evaluation indexes is defined as

$$
\begin{gathered}
H_{i}=\frac{-1}{\ln m} \sum_{j=1}^{m}\left(f_{i j} \ln f_{i j}\right) \\
f_{i j}=\frac{1+b_{i j}}{\sum_{j=1}^{m}\left(1+b_{i j}\right)}(i=1,2, \ldots, n ; j=1,2, \ldots, m)
\end{gathered}
$$

(4) Calculating entropy weight $w$

$$
w_{i}=\frac{1-H_{i}}{n-\sum_{i=1}^{n} H_{i}}
$$

where $\sum_{i=1}^{n} w_{i}=1$

\subsubsection{Closeness Degree and Comprehensive Evaluation}

Closeness degree is the proximity degree between the evaluated samples and a standard sample. Therefore, each evaluation scheme can be sequenced based on the closeness degree, or be classified according to the closeness degree of standard value. Considering the detailed evaluation significance, the Euclid closeness degree $\rho H_{j}$ is used as the evaluation standard, using $(\cdot,+)$ algorithm (first by multiplication, then by addition) to calculate and build up closeness degree for the composite fuzzy matter-element $R_{\rho H}$ (Cai 1994):

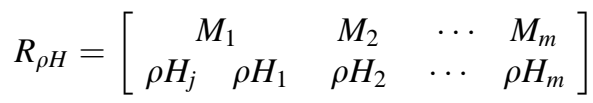

where $\rho H_{j}=1-\left(\sum_{i=1}^{n} K_{i} \Delta_{i j}\right)^{1 / 2}(\mathrm{j}=1,2, \ldots, \mathrm{m})$, and $K_{i}$ is the relational degree. 


\subsection{Conclusions}

By considering multiple factors, the new model can overcome the limitations of single-factor methods. In this chapter, most of parameters and methods were considered in order to eliminate subjective judgments. These variables included rock brittleness index $R_{b}$, Russense's $R_{\theta}$, Kidybinski's $W_{\text {et }}$, the surrounding rockmass stress $\sigma_{1}$ and $\sigma_{\theta}$, and rock strength $\sigma_{c}$ and $\sigma_{t}$.

The occurrence of rockburst was correlated not only with the physi-mechanical parameters of rockmass, but also with the surrounding mining environment. This research was intended to advance the development of predicting rockburst model based on fuzzy matter element method and measurement data.

Proposed model was based on fuzzy matter-element analysis, combining with the concept to Euclid closeness degree, an integrated rockburst multi-index predicted model was proposed. In this model, the rock brittleness $(B)$, the major principal stress $\left(\sigma_{1}\right)$, rock integrity $\left(k_{V}\right)$ and impact energy parameters $\left(W_{C F}\right)$ were all considered. At the same time, the entropy theory was introduced to determine the weight of each evaluation index, preventing the subjectivity of weight distribution. Finally, we recommend the fuzzy matter-element model on predicting rockburst method in field.

\section{References}

Adoko AC, Gokceoglu C, Wu L (2013) Knowledge-based and data-driven fuzzy modeling for rockburst prediction. Int J Rock Mech Min Sci 61:86-95

Barton N, Lien R, Lunde J(1974) Engineering classification of rock masses for the design of tunnel support. Rock Mech 6(4):189-236

Blake W, Hedley DGF (2003) Rockbursts: case studies from North American hard-rock mines. SME

Cai W (1994) Matter element model and its application. Scientific and Technical Documents Publishing House, Beijing, pp 256-68 (in Chinese)

Canadian Rockburst Research Program (1996) Rockburst research handbook: a comprehensive summary of five years of collaborative research on rockbursting in hard rock mines. CAMIRO Mining Division, CRRP, Sudbury ON

Chen HJ, Li NH, Nie DX, Shang YQ (2002) Artificial neural network model for prediction of rockburst. Chin J Geotech Eng 24(2):229-232 (in Chinese)

Chen HQ, Wang N, Sheng YR (2007) Application of fuzzy matter element model in evaluation of water security based on Euclid approach degree. J Xi'an Univ Technol 23:37-42 (in Chinese)

Cook NGW (1965) The failure of rock. Int J Rock Mech and Min Sci Geomech Abstr Pergamon 2 (4):389-403

David KWN, Cai W (1997) Treatingnon-compatibility problem from matter element analysis to extenics. ACM Sigice Bull 22:2-9

Dou LM, Lu CP, Mu ZL (2009) Prevention and forecasting of rock burst hazards in coal mines. Min Sci Tech (China) 19(5):585-591

Gao HX (1999) Multivariate statistical analysis application. Beijing University Press, Beijing

Gong FQ, Li XB (2007) Rockburst intensity and grading forecast based on Byesian distance discriminant analysis method. Chin J Rock Mech Eng 26(5):1012-1018

He YX (2011) Risk assessment of urban network planning in china based on the matter-element model and extension analysis. Int J Electr Power Energy Syst 33:775-782 
Heckerman D (1990) Probabilistic similarity networks. Networks 20(5):607-636

Hedley DGF (1992) Rockburst handbook for Ontario hardrock mines. Canmet SP92-1E

Hoek E, Brown ET (1980) Empirical strength criterion for rock masses. J Geotech Geoenviron Eng 106(ASCE 15715)

Hou FL, Wang MQ (1989) Criterion and prevention measures on rockburst in circular tunnel. In: Chinese Society for Rock Mechanics Engineering, Proceedings of the 2th National Rock Mechanics and Engineering. Knowledge Press. Beijing

Jensen FV, Kjærulff U, Kristiansen B (2001) The SACSO methodology for troubleshooting complex systems. AI EDAM 15(04):321-333

Kemmerer B, Mishra S, Shenoy PP (2002) Bayesian casual maps as decision aids in venture capital decision making: methods and applications. Acad Manage, pp C1-C6

Kidybiński A (1981) Bursting liability indices of coal. Int J Rock Mech Min Sci Geomech Abstr 18(4):295-304

Li J, Qian YH, Da PL (2011) The rockburst experiment usage of similar material and the mechanism of the energy releasing. Adv Mater Res 295:378-82

Liu ZJ, Li JL (2007) Comprehensive prediction method for rockburst based on fuzzy probability theory. J Yangtze River Sci Res 24:42-45

Liu D, Zou Z (2012) Water quality evaluation based on improved fuzzy matter-element method. J Environ Sci 24(7):1210

Marek U (2009) Monitoring of methane and rockburst hazards as a condition of safe coal exploitation in the mines of Kompania Weglowa SA. Proc Earth Planet Sci 1(1):54-59

Marian T (2011) Directions of changes of hard coal output technologies in Poland. Min Sci Tech (China) 21(1):1-5

Müller L (2007) Fundamentals of rock mechanics. Blackwell, London

Patynska R, Kabiesz J (2009) Scale of seismic and rock burst hazard in the Silesian companies in Poland. Min Sci Tech (China) 19(5):604-608

Ren XS, Yu XL (1999) Multivariate statistical analysis. China Statistics Press, Beijing

Russenes BF (1974) Analyses of rockburst in tunnels in valley sides. Norwegian Institute of Technology Google Scholar

Singh SP (1988) Burst energy release index. Rock Mech Rock Eng 21(2):149-155

Singh SP (1989) Classification of mine workings according to their rockburst proneness. Min Sci Tech 8(3):253-262

Srinivasan C, Arora SK, Yaji RK (1997) Use of mining and seismological parameters aspremonitors of rockbursts. Int J Rock Mech Min Sci 34:1001-1008

Stewart RD (1995) Development of seismic risk assessment method for application to rockburst-prone sites in deep-level South African gold mines. Int J Rock Mech Min Sci Geomech Abst, pp 32297A-297A(1)

Tao ZY (1987) Rockburst determination in high in-situ stress region. J People Yangtze River 25(5):32

Tan Y, Sun GZ, Guo Z (1991) A composite index K(rb) criterion for the ejection characteristics of the burst rock. Chinese J Geol 2: 193-200

Turchaninov IA, Markov GA (1981) Conditions of changing of extra-hard rock into weak rock under the influence of tectonic stresses of massifs. ISRM International Symposium

Wang YH, Li WD, Li QG, Xu Y, Tang GH (1998) Comprehensive evaluation method of fuzzy mathematics for the prediction of rockburst. Chinese J Rock Mech Eng 5(17):493-501

Wang CL, Wu $\mathrm{AX}, \mathrm{Lu} \mathrm{H}$ et al (2015) Predicting rockburst tendency based on fuzzy matter-element model. Int J Rock Mech Min Sci 75: 224-232

Weidl G, Madsen AL, Dahlquist E (2003) Object oriented Bayesian networks for industrial process operation. In: First Bayesian Applications Modeling Workshop, http://www.intel.com/ research/events/UAI03_workshop

Wiebols GA, Cook NGW (1968) An energy criterion for the strength of rock in polyaxial compression. Int J Rock Mech Min Sci Geomech Abstr 5(6):529-549

Xu LS, Wang LS, Li YL (2002) Study on mechanism and judgement of rockbursts. Chinese J Rock Soil Mech 23:300-303 
Yu HC (2009) Prediction method of rockburst proneness based on rough set and genetical gorithm. J Coal Sci Eng 15(4):367-373

Zhang JS, Lu JY, Jia YR (1991) Study on tunnel rockburst in Tian Sheng Qiao sub-hydropower station. J Hydroelectric Power (10):34-37

Zhu JR (2010) Application of fuzzy matter-element model based on coefficients of evaluation in rockburst (Natural Science Edition). J Hunan Univ Sci Technol

Open Access This chapter is licensed under the terms of the Creative Commons Attribution-NonCommercial 4.0 International License (http://creativecommons.org/licenses/by-nc/ $4.0 /$ ), which permits any noncommercial use, sharing, adaptation, distribution and reproduction in any medium or format, as long as you give appropriate credit to the original author(s) and the source, provide a link to the Creative Commons license and indicate if changes were made.

The images or other third party material in this book are included in the book's Creative Commons license, unless indicated otherwise in a credit line to the material. If material is not included in the book's Creative Commons license and your intended use is not permitted by statutory regulation or exceeds the permitted use, you will need to obtain permission directly from the copyright holder.

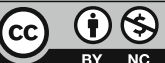

